\title{
Expresiones Artísticas ineludibles ante un confinamiento.
}

\section{Inesidible artistic expressions in confinement}

\section{Mạ Victoria Márquez Casero}

Universidad de Málaga

victoriamarquez@uma.es

\section{Leticia M. Vázquez Carpio}

Universidad de Málaga

lvazquez@uma.es
Recibido 01/09/2020 Revisado 09/10/2020

Aceptado 09/10/2020 Publicado 30/04/2021

\section{Resumen:}

El cuerpo ha sido un referente artistico, el pilar central de muchas creaciones. El ser humano es un hibrido de lo corporal y lo espiritual. No hay cuerpo sin mente ni mente sin cuerpo.

Cada artista plasma en sus obras una intencionalidad, transmite un concepto, una idea, una propuesta, refleja un malestar, una carencia o vuelca en las mismas su "yo" reflexivo y filosofico.

\section{Abstract:}

The body has been an artistic reference, the central pillar of many creations. The human being is a hybrid of the corporeal and the spiritual. Not there is a body without a mind and a mind without a body. Each artist embodies an intentionality in their works, transmits a concept, an idea, a proposal, reflects a discomfort, a lack or he dumps his reflective and philosophical "I" into them.

\section{Palabras Clave:}

Confinamiento, Arte, Cuerpo

Key words:

Art, body, confinement

\section{Sugrencias para citar este artículo,}

Márquez Casero, Ma Victoria; Vázquez Carpio, Leticia M. (2021). Expresiones artísticas ineludibles ante un confinamiento. Tercio Creciente (Monográfico extraordinario V), (pp. 213-223), https://dx.doi.org/10.17561/rtc.extra5.5722

MÁRQUEZ CASERO, Ma VICTORIA; VÁZQUEZ CARPIO, LETICIA M. Expresiones artísticas ineludibles ante un confinamiento. Tercio Creciente (Monográfico extraordinario V) abril 2021, pp. 213-223, https://dx.doi.org/10.17561/rtc.extra5.5722 


\section{Introducción}

El cuerpo ha sido un referente artístico, el pilar central de muchas creaciones. El ser humano es un hibrido de lo corporal y lo espiritual. No hay cuerpo sin mente ni mente sin cuerpo.

Cada artista plasma en sus obras una intencionalidad, transmite un concepto, una idea, una propuesta, refleja un malestar, una carencia o vuelca en las mismas su "yo" reflexivo y filosófico.

Artistas como Yves Klein, trabajaron el cuerpo como herramienta pictórica, "Pinceles vivos". Spencer Tunick combina la belleza corporal de las masas con los espacios públicos, jugando con lo corpóreo de la instalación y la mente del espectador. Marina Abramović, experimenta con su propio cuerpo y estudia la reacción del público. De igual Forma Helena Almeida, partiendo de su propio cuerpo trabaja con la fotografía y la pintura expandida, convirtiéndose en pionera del uso del propio cuerpo en las creaciones artísticas y en un referente para el feminismo internacional.

Por otra parte, encontramos artistas que centran sus obras en la psique, como el Neoplasticismo de Mondrian, cuyo arte estuvo relacionado íntimamente con sus conocimientos y estudios filosóficos y espirituales. Oel expresionismo alemán, movimiento heterogéneo que buscaban reflejarla visión interna del artista, La abstracción americana con la figura de Pollock y Rothko con su riqueza de color con límites indefinidos. Querían representar las más básicas emociones universales. O el Nuevo expresionismo de Jorge Rando, centrado en el concepto, en la Espiritualidad y el Humanismo.

Todos centrados en el ser humando, tratando el cuerpo desde un punto de vista concreto. Manifestando esa inquietud que el artista o la artista expresa en su obra lanzando continuas preguntas al espectador

Hoy día estamos atravesando un hecho social desconocido, una pandemia que nos ha obligado a realizar determinadas acciones en contra de nuestra voluntad. Hemos estado confinados ¿Cuál habrá sido la reacción ante esaprivacidad de sentimientos, de contactos de vivencias, de libertad? ¿Cuálhabrá sido la percepción del artista ante las informaciones recibidas, antela desescalada...? Cómo ha actuado nuestros cuerpos, nuestra psique Desde un punto de vista artístico, debemos analizar cómo hemosreaccionado los artistas y las artistas ante las circunstancias vividas pordicha pandemia.

Si ha servido como foco de creación o como foco de inhibición. El tiempo ganado no sustituye la fluidez mental necesaria para crear. La incertidumbre vivida, influye en lo físico y en lo psíquico. 
ISSN: $2340-9096$

https://doi.org/10.17561/rtc.extra5.5722

Las redes sociales se han convertido en las transmisoras sociales y por consiguiente en transmisoras artísticas. Se ha creado lo que se visualizaba desde las ventanas, se ha cantado y mostrado el arte desde los balcones. se ha abierto aún más a la difusión en redes; mostrándose desde sus propias casas, realizando grabaciones, conciertos, exposiciones ceñidas a un enlace.

Como artistas, somos seres libres que necesitamos nuestro espacio, percibimos todas aquellas sensaciones inocuas al ojo y nos desencadenan impulsos para transmitirlas. Nos preguntamos si tales circunstancias afectarán al artista y por ende al arte y si cambiará el concepto o el proceso artístico.

\section{Expresiones artísticas ineludibles ante un confinamiento}

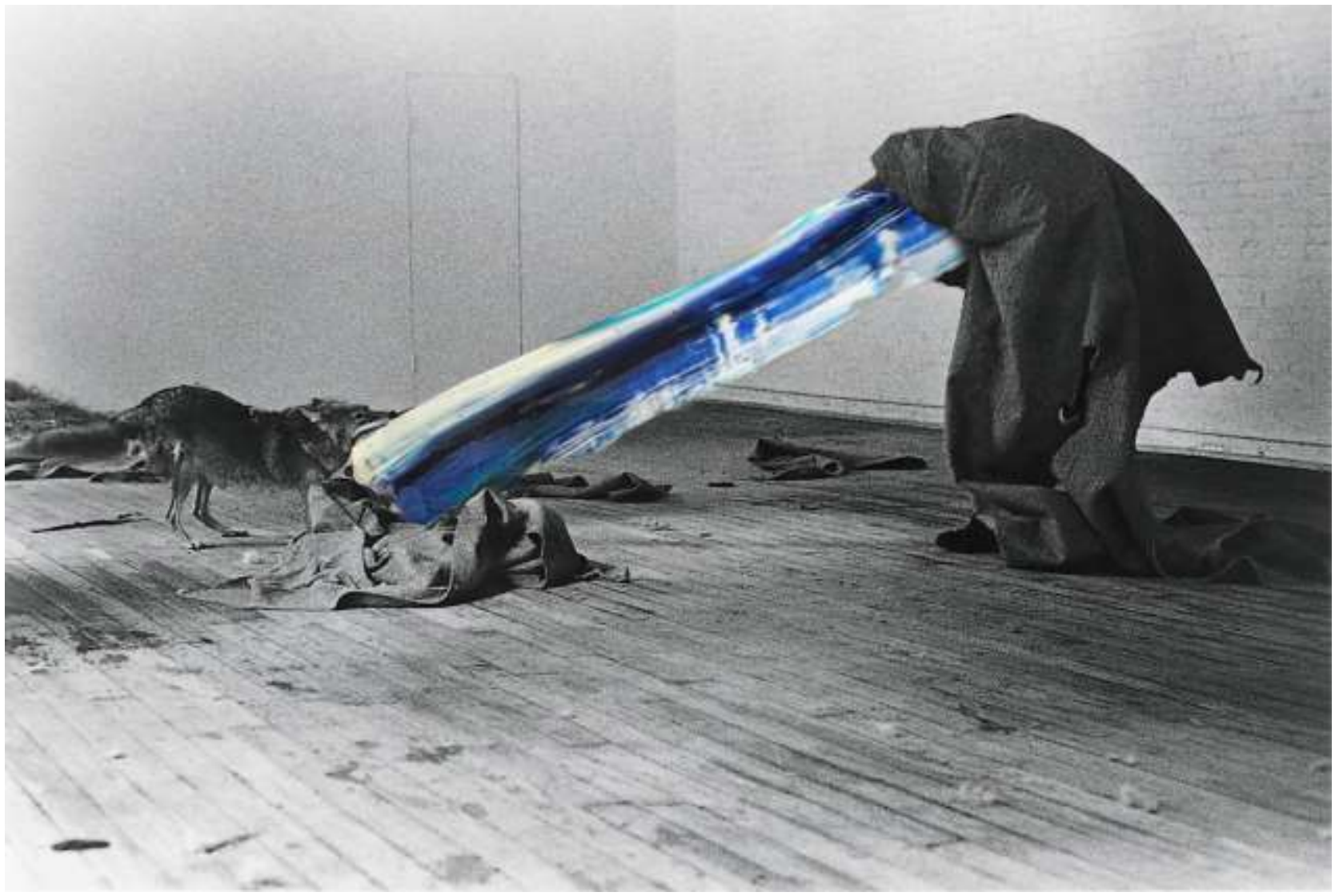

El confinamiento contra el creador, (2020) Leticia A. Vázquez Carpio y $\mathrm{M}^{\mathrm{a}}$ Victoria Márquez Casero (Fotograma original extraído de Me gusta América y América le gusto yo, 1974. Autor: Joseph Beuys).Fuente: Propia. 
El cuerpo ha sido un referente artístico, el pilar central desde la génesis de la creación. El ser humano es un hibrido de lo corporal y lo espiritual. no podemos disociarlo. No haycuerpo sin mente, ni mente sin espíritu. El arte nos permite materializar el espíritu creador artístico. Sirve de canal comunicativo entre nuestro yo y nuestro mundo. Entrelos artistas que comulgamos con tal realidad nos encontramos las palabras de Jean Dubuffet:

"El arte se dirige a la mente, y no a los ojos. Siempre ha sido considerado de esta manera por pueblos primitivos, y ellos tienen razón. El arte es un idioma, el instrumento del conocimiento, el instrumento de la comunicación."

Cada artista plasma en sus obras una intencionalidad, transmite un concepto, una idea, una propuesta, refleja un malestar, una carencia o vuelca en las mismas su "yo" reflexivo y filosófico. Desde el S. XX el número de artistas que utilizan el cuerpo como expresión, lejos de utilizarlo con las normas academicistas, se ha visto consolidado. Surgen así creaciones artistitas innovadoras y personalizadas, en las que el cuerpo se convierte en el propio pilar de la creación, bien como herramienta, bien como lugar expositivo, dando pie al Body Art "Tipo de arte en el que el artista utiliza su propio cuerpo como medio; está íntimamente ligado al arte conceptual y al Performace Art", ${ }_{1}^{1}$ a videocreaciones oinstalaciones.

Avistamos artistas que nos presentan el cuerpo desde lo corpóreo.

"Mientras Callahan y Doisneau realizaban fotografías agresivas heterosexuales, el artista norteamericano Robert Rauscheberg y su mujer, la artista Susan Weil, hacían copias de tamaño natural de su cuerpo desnudo sobre papel sensible. Para realizar estas obras, Rauscheberg y Weil se introducçian lietramente en ellas, situando el cuerpo sobre el papel que después revelaban a la luz del sol. Estasimágenes son parientes del arte expresionista de Jckon Pollock, Willem de Kooning y otros llamados "action painters", porque contienen huellas literales del esfuerzo físisco que hay en la pintura. Como ellos, Rauscheberg y Weil pretenden dejar un indicio de su cuerpo, más que representarlos y su cuerpo aparece no como imagen, sino como huella deque alguna vez estuvo allí."

En paralelo a lo indicado, nosotras no pretendemos representar el arte y si dejar en la imagen un indicio de ese arte vivido o no vivido, de esa lucha ganada o no ganada de lacreatividad artística ante la pandemia experimentada.

${ }^{1}$ Chilvers, I (2004) Diccionario del arte del siglo XX. Editorial Complutense (p. 110)

${ }^{2}$ Pultz, J (2003) La fotografía y el cuerpo. Ediciones AKAL Madrid (p.109) 
Artistas como el neodadaísta Yves Klein, trabajaron el cuerpo como herramienta pictórica, "Pinceles vivos". Otros como el fotógrafo estadounidense Spencer Tunick combina la belleza corporal de las masas con los espacios públicos, en ocasionesconocidas como instalaciones, jugando con lo corpóreo de la instalación y la mente, conla reflexión del espectador. Otra artista conceptual que trabaja la performace, siendo ella la propia protagonista de las mismas, es Marina Abramović, experimenta con su propio cuerpo y estudia la reacción del público ante determinadas situaciones. En el 2020, el MoMA inauguró una performance de dicha artista convirtiéndose en el suceso artístico del año en Nueva York. En el vestíbulo del museo, Sentada en una silla de madera, sin moverse y sin hablar, junto a una mesa pequeña con una silla vacía. Los visitantes podían sentirse participes de la obra al sentarse frente a ella y observarla durante el tiempo que cada persona desease. Declararon que habían experimentado una paz interior inefable, llegando algunos incluso a llorar. $^{3}$

De igual Forma Helena Almeida, partiendo de su propio cuerpo trabaja con la fotografíay la pintura expandida, convirtiéndose en pionera del uso del propio cuerpo en las creaciones artísticas y en un referente para el feminismo internacional. Hay también artistas como Abel Azcona, contemporáneo español vinculado al arte conceptual quienes se centran en la performance postulando su rebelión contra la sociedad,expresando un notorio talante político y autobiográfico.

Por otra parte, encontramos quienes que centran sus obras en la psique, como el Neoplasticismo de Mondrian, cuyo arte estuvo relacionado íntimamente con sus conocimientos y estudios filosóficos y espirituales. O el expresionismo alemán, movimiento heterogéneo que abarcó todas las artes. Buscaban reflejar la visión internadel artista, su expresión frente a la visualización; no querían describir y sí expresar los sentimientos, como ya hicieron autores como Goya o el Greco. Surgió posteriormente la Abstracción Americana, "las pinturas del Expresionismo Abstracto, que muestran los resultados de las acciones de un cuerpo" " con la figura de Pollock y Rothko con su riqueza de color con límites indefinidos. Querían representar las más básicas emocionesuniversales. O el Nuevo Expresionismo de Jorge Rando, centrado en el concepto, en la Espiritualidad y el Humanismo.

3 Vicent, M (2015) El cuerpodel artista como arte. El Pais. https://elpais.com/cultura/2015/04/26/actualidad/1430075158_764618.html 
Todos centrados en el ser humando, tratando el cuerpo desde un punto de vista concreto. Manifestando esa inquietud que el artista o la artista expresa en su obra lanzando continuas preguntas al espectador

Otra temática que nos atañe es el concepto de confinamiento. No nos enfrentamos a untérmino nuevo en el decálogo del artista. Artísticamente hablando pude derivarse en varias connotaciones. En lo más íntimo, la creación en sí misma, es un acto solitario, es una entrega sin límite, que abarca cualquier instante y cualquier hora del día. La mente, el cuerpo y el espíritu creador conviven en un mismo ente indisociable en continua impregnación de todo aquello que le rodea.

Este aislamiento artístico ha sido, la trama, para artistas como Joseph Beuys, en la obra"Me gusta América y América le gusto yo" o más conocida como "El coyote", performance en la que el artista se confinó junto con un coyote salvaje con varios elementos: una manta de fieltro (conocido objeto fetiche del artista), unos guantes, un bastón y un periódico. Beuys se centró en la crítica que existía en aquel entonces sobre la distinción de arte y vida. Para él, todo ser humano lleva intrínseco una creatividad latente como bien lo indicó" todo hombre es un artista" y por consiguiente cualquier actividad genera un potencial artístico. Sus esculturas sociales, como él propio artista las denominó, lejos del academicismo formal, se centraban en la transformación cultural y social. Base de la narrativa en la que nos encontramos y base de actual trabajo. A Beuys, según declaraciones del propio autor, le movió el deseo de un aislamiento voluntario. Llegó a Estados Unidos en 1974 y fue envuelto en fieltro y trasladado en unaambulancia para no tocar Tierra a su llegada con la finalidad de que su primer contacto fuese con el coyote, mostrando aquí la reivindicación social de las poblaciones nativas, frente a la modernidad, asilándose previamente de toda comunicación mediática.

Si comparamos con la situación vivida, nos encontramos con la misma temática, pero con los papeles invertidos. El confinamiento ha sido involuntario y los medios mediáticosexcesivos.

Contra todo pronóstico, Beuys, a pesar de iniciar el confinamiento peleándose con el coyote por la manta, acabó estableciendo con él, lo que llamaríamos casi una relación cordial; tras tres días confinados, terminaron compartiéndola. ¿Qué habría sucedido si Beuys se hubiera confinado con el coyote durante 50 días?

\footnotetext{
4 Pultz, J (2003) La fotografía y el cuerpo. Ediciones AKAL Madrid (p.109)
} 
Conocemos esta acción gracias a la documentación fotográfica. Las redes sociales, inicialmente fundadas para divulgar y unificar, se han convertido en las transmisoras sociales y por consiguiente en transmisoras artísticas.

Hoy día estamos atravesando un hecho social desconocido, una pandemia que nos ha obligado a realizar determinadas acciones en contra de nuestra voluntad. Hemos estado confinados ¿Cuál habrá sido la reacción ante esa privacidad de sentimientos, de contactos de vivencias, de libertad? ¿Cuál habrá sido la percepción del artista ante las informaciones recibidas? Nos han encerrado, en nuestro propio espacio con su correspondiente privacidad. El tiempo ganado no sustituye la fluidez mental necesaria para crear. La incertidumbre vivida, influye en lo físico y en lo psíquico.

Pintores y Escultores han mostrado aquello que visualizan desde sus ventanas, aquellos sentimientos que les producían dichas circunstancias. Se han abierto aún más a la difusión en redes ¿por necesidad, por objetividad? realizando grabaciones, conciertos, exposiciones ceñidas a un enlace. En la sociedad ha germinado esa creatividad oculta que quizás por falta de tiempo muchos individuos no dejaban aflorar.

Hemos teletrabajado y criticado a las redes sociales, todos estamos cansados de las NNTT, pero la realidad es que la sociedad ha generado un avance en la comunicación telemática, por necesidad, evidentemente; Pero..., ¿ ha afectado dicha situación al arte?

David Catá, artista que reclama la percepción y utiliza el cuerpo como formato artístico,es uno de los que han publicitado en redes sociales sus creaciones realizadas a partir dela pandemia, tanto musical como fotográfica. Su proyecto: la vida tras la ventana, realizado en los días de confinamiento es uno de los ejemplos.

Muchos artistas solían trabajar en un estudio al que no han podido asistir durante meses, y eso ha hecho que el hogar cobrase un papel casi protagonista en las creaciones. Una función como escenario forzoso en el que todos los elementos presentes han sido parte de creaciones. Encontramos un ejemplo en la obra de Pablo Fernández Pujol, quien, en el 2010, experimentó voluntariamente un confinamiento. 
ISSN: 2340-9096

https://doi.org/10.17561/rtc.extra5.5722

(i)
Monográfico

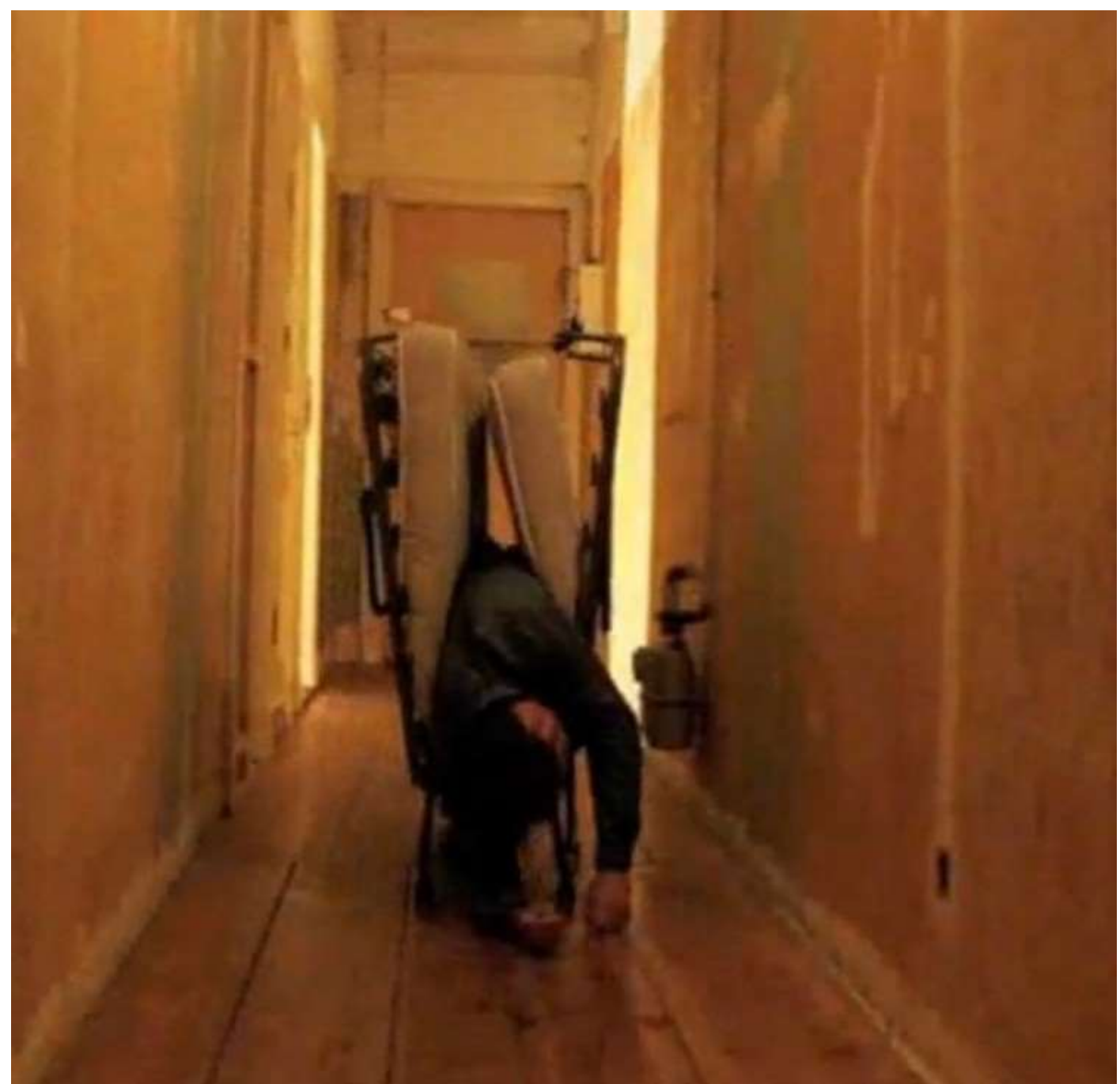

Figura 4

Retrato de un confinamiento, 2010. Autor: Pablo

Fernández Pujol. Fuente: artista. 


\section{Tercio Creciente}

Revista de Estudios en Sociedad, Artes y Gestión Cultural

ISSN: 2340-9096

https://doi.org/10.17561/rtc.extra5.5722 (i) 0
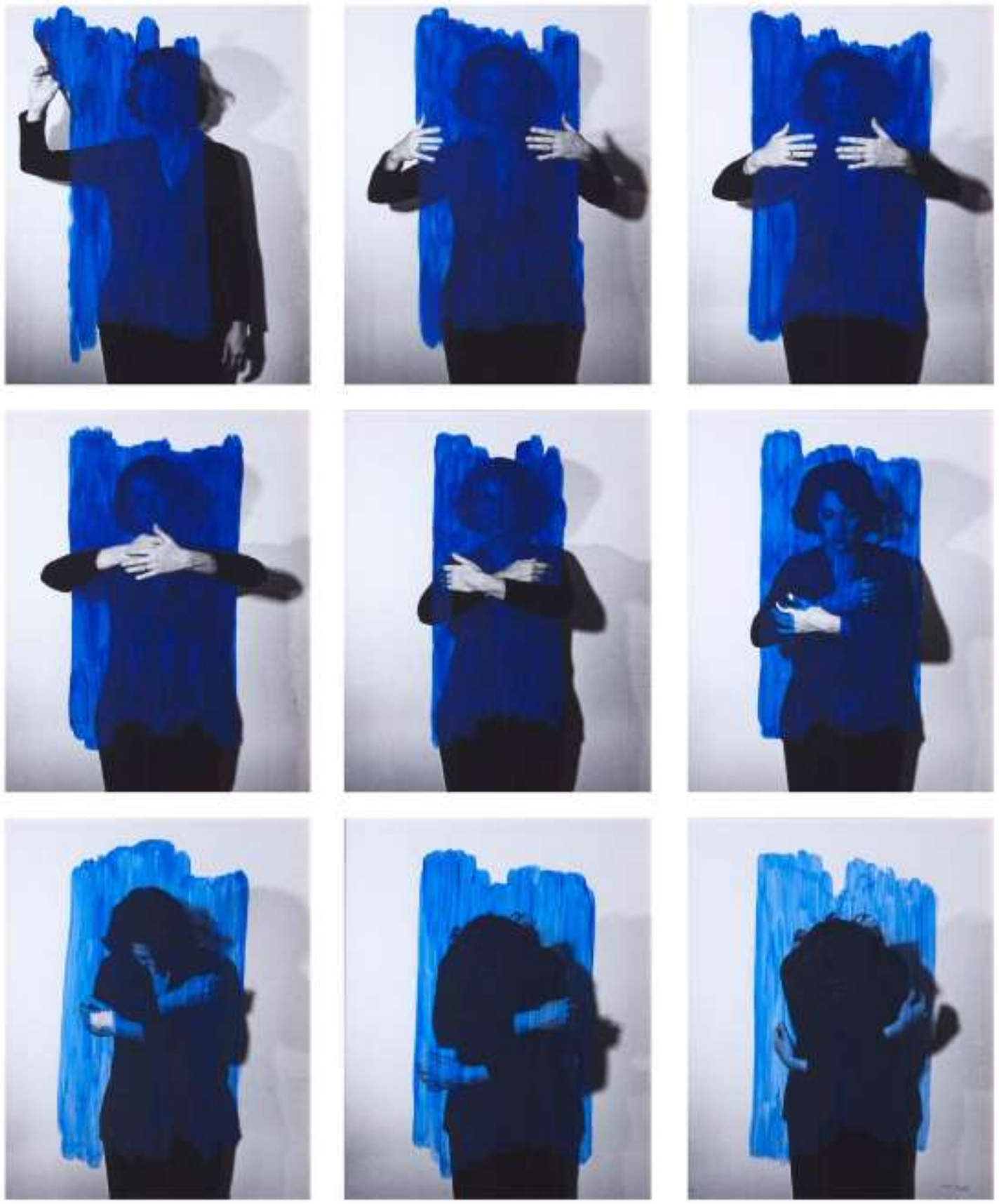

Figura 3. Para un enrriquecimento interior, 1976.

Autor: Helena Almeida. Fuente: Colección Helga de Alvear 
También podríamos decir que la artista, ya mencionada, Helena Almeida, de alguna forma se confinaba en sus propios cuadros, convirtiéndose en lienzo de su obra. Se planteaba así el papel del cuerpo del creador, desde el punto de vista más físico. Nos habla de habitar los espacios.

Como creadoras hemos experimentado, en las circunstancias vividas, la importancia de los materiales artísticos. Hay varios elementos imprescindibles para sobrevivir a un confinamiento, tanto a nivel doméstico como artístico y uno de ellos sin duda es el papel. Elemento austero presente en el origen de una creación. Artistas como David Segarra han retratado su incertidumbre ante esta nueva situación experimentada en su obra "We all are going to die", en la que una hado de acumulación de papel rasgado nostraslada a un paisaje limpio, impoluto, pero a su vez inquietante.

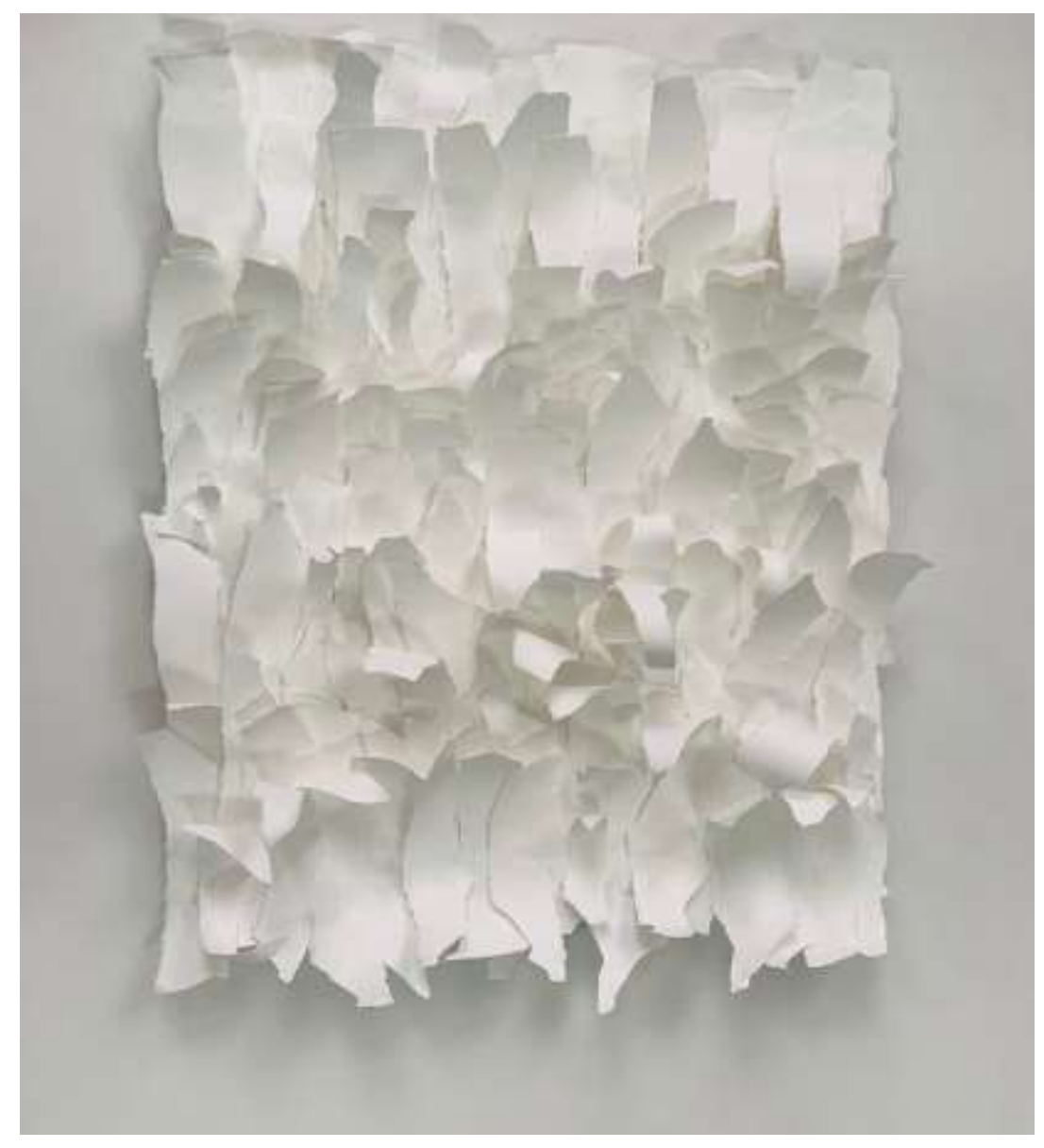

Figura 2. We all are going to die, 2020 Autor: David Segarra. Fuente: Artista. 
El arte vanguardista se define precisamente como aquel en el que el autor o autora marca su propio signo en sus obras, es precisamente este sello lo que definen las distintas corrientes artísticas y lo que da tesón al propio artista, lo que maraca su sello personal.

Todas nuestras acciones y por consiguiente nuestro cuerpo se ve modificado por circunstancias sociales que nos condicionan lo que somos y lo que hacemos.

Actualmente, hemos pasado por uno de los peores momentos que la historia podrá contar, por una pandemia que ha modificado las circunstancias sociales, económicas y las relacionales de la humanidad.

Nos preguntamos si tales circunstancias afectarán al artista y por ende al arte y si cambiará el concepto o el proceso artístico.

Como artistas, somos seres libres que necesitamos nuestro espacio, percibimos todas aquellas sensaciones inocuas al ojo y nos desencadenan impulsos para transmitirlas

a través de las propias creaciones.

En la imagen del presente fotoensayo, mostramos una reinterpretación, un apropiacionismo, de un fotograma de la obra de Beuys en el que el arte y en concreto la pintura, sirve de puente tensor entre el Confinamiento y el propio creador.

"Estamos confinados en nuestra propia obra". En palabras del Maestro Jorge Rando "Atravesamos el espacio, pero estamos confinados en ella" 
